\title{
Pengaruh Customer Perceived Value (Persepsi Nilai oleh Pelanggan) dan Customer Perceived Quality (Persepsi Mutu Oleh Pelanggan) terhadap Loyalitas Pelanggan pada CV. Qyta Dental Persada Laboratory Palembang
}

\author{
Nenny Octarinie \\ Dosen Tetap Fakultas Ekonomi Universitas Palembang
}

\begin{abstract}
Abstrak
Penelitian ini bertujuan untuk mengetahui pengaruh Customer Perceived Value (Persepsi Nilai oleh Pelanggan) dan Customer Perceived Quality (Persepsi Mutu Oleh Pelanggan) terhadap Loyalitas Pelanggan pada CV.Qyta Dental Persada Laboratory Palembang. Sampel pada penelitian ini berjumlah 50 orangresponden.Data yang digunakan adalah data primer yang dianalisis dengan menggunakan persamaan regresi linier bergandaa, uji hipotesis (uji t dan uji f), serta koefisien determinasi $\left(\mathrm{R}^{2}\right)$. Hasil penelitian diperoleh $\mathrm{Y}=2,093+0,321 \mathrm{X} 1+$ 0,563X2. Konstanta sebesar 2,093loyalitas pelanggansebelum dipengaruhi oleh Customer Perceived Value (Persepsi Nilai oleh Pelanggan) dan Customer Perceived Quality (Persepsi Mutu Oleh Pelanggan) terhadap Loyalitas Pelanggan pada CV.Qyta Dental Persada Laboratory Palembang.Hasil perhitungan menunjukkan nilai $\mathrm{R}^{2}=0,338$. Hal ini berarti bahwa sebesar 33,8\% variasi naik turunnya loyalitas pelanggan dipengaruhi variabel Customer Perceived Value (Persepsi Nilai oleh Pelanggan) dan Customer Perceived Quality (Persepsi Mutu Oleh Pelanggan). Sedangkan sisanya sebesar $66,2 \%$ dipengaruhi oleh variabel lain yang tidak terdapat pada penelitian ini.
\end{abstract}

Kata Kunci :Customer Perceived Value, Customer Perceived Quality, Loyalitas Pelanggan

\section{PENDAHULUAN}

\subsection{Latar Belakang}

Industri jasa yang ada di dunia bermacam-macam,diantaranya dalam bidang kesehatan, bidang pendidikan, bidang telekomunikasi, bidang keuangan dan bidang transportasi (Tjiptono,2016 :143). Bidang kesehatan merupakan sektorpelayanan utama di berbagai negara karenamemegang peranan vital dalam menjaga danmeningkatkan kesehatan masyarakat untukmencapai tujuan suatu negara. Saat ini industri jasa di bidang kesehatan merupakan salah satupeluang bisnis yang menjanjikan dengantingginya kompetisi yang ada dan pertumbuhanyang cepat (Kevin Julian, 2012 :17).

CV. Qyta Dental Persada Laboratory Palembang sebagai salah satu perusahaan yang bergerak di bidang pelayanan kesehatan. Masalah utama sebagai sebuah lembaga jasa pelayanan kesehatan adalah semakin banyaknya pesaing. Oleh karena itu, CV. Qyta Dental Persada Laboratory Palembang dituntut untuk selalu menjaga kepercayaan konsumen dengan meningkatkan kualitas pelayanan agar kepuasan konsumennya meningkat. Pihak CV. Qyta Dental Persada Laboratory Palembang perlu secara cermat menentukan kebutuhan konsumen sebagai upaya untuk memenuhi keinginan dan meningkatkan kepuasan atas pelayanan yang diberikan (Rangkuti, 2008: 57).

Memberikan pelayanan dengan kualitas terbaik, bukanlah sesuatu yang mudah bagi pengelola CV.Qyta Dental Persada Laboratory Palembang karena pelayanan yang diberikan akan menyangkut kualitas hidup para konsumen sehingga bila terjadikesalahan dalam tindakan medis dapat berdampak buruk bagi konsumen.CV. Qyta Dental Persada Laboratory Palembang sebagai bagian dari 
sistem kesehatan nasional dituntutuntuk meningkatkan kualitas penyediaan fasilitas, pelayanan dan kemandirian. Dengan demikian CV.Qyta Dental Persada Laboratory Palembang merupakan salah satu pelaku pelayanan kesehatan yang kompetitif harus dikelola oleh pelaku yang mempunyai jiwa wirausaha yang mampu menciptakan efisiensi, keunggulan dalam kualitas danpelayanan, keunggulan dalam inovasi serta unggul dalam merespon kebutuhanpasien (Bernard Widjaja, 2009: 77).

Dalam menerima dan melayani konsumendengan berbagai karakteristik, CV. Qyta Dental Persada Laboratory Palembangharus melengkapi diri supaya senantiasa mendengarkan suara konsumen, dan memiliki kemampuan memberikan respon terhadap setiap keinginan, harapan konsumen dan tuntutan pengguna jasa sarana pelayanan kesehatan.

Dari uraian di atas sangatlah perlu dilakukan penelitian tentangsejauhmana tingkat kepuasan konsumen terhadap pelayanan CV. Qyta Dental Persada Laboratory Palembangditinjau dari sisi Customer Perceived Value (Persepsi Nilai oleh Pelanggan) dan Customer Perceived Quality (Persepsi Mutu Oleh Pelanggan) sehingga dapat meningkatkan loyalitas pelanggan terhadap CV. Qyta Dental Persada Laboratory Palembang.

\subsection{Perumusan Masalah}

Berdasarkan uraian latar belakan diatas maka dapat dirumuskan masalah sebagai berikut :

a. Bagaimana Pengaruh Customer Perceived Value (Persepsi Nilai oleh Pelanggan) dan Customer Perceived Service Quality (Persepsi Mutu Oleh Pelanggan) terhadap Customer Loyalty (Loyalitas Pelanggan) terhadap loyalitas pelanggan pada CV. Qyta Dental Persada Laboratory Palembang

b. Variabel manakah Customer Perceived Value (Persepsi Nilai oleh
Pelanggan) dan Customer Perceived Service Quality (Persepsi Mutu Oleh Pelanggan) terhadap Customer Loyalty (Loyalitas Pelanggan)yang memiliki pengaruh paling dominan terhadap loyalitas pelanggan pada CV. Qyta Dental Persada Laboratory Palembang.

\subsection{Tujuan Penelitian}

Tujuan dari penelitian ini adalah:

a. Untuk menganalisis pengaruh variabel yaitu Customer Perceived Value (Persepsi Nilai oleh Pelanggan) dan Customer Perceived Service Quality (Persepsi Mutu Oleh Pelanggan) secara parsial dan simultan terhadap loyalitas pelanggan pada CV. Qyta Dental Persada Laboratory Palembang

b. Untuk menganalisis pengaruh yang paling dominan diantara masingmasing variabel yaitu Customer Perceived Value (Persepsi Nilai oleh Pelanggan) dan Customer Perceived Service Quality (Persepsi Mutu Oleh Pelanggan) terhadap loyalitas pelanggan pada CV.Qyta Dental Persada Laboratory Palembang.

\section{TINJAUAN PUSTAKA}

\subsection{Landasan Teori}

\section{A. PemasaranJasa}

Rangkuti (2002 : 26) menyebutkan bahwa jasa merupakan pemberian suatu kinerja atau tindakan tak kasat mata dari suatu pihak ke pihak lain. Sedangkan menurut Kotler (2002:486) mendefisikan jasa sebagai setiap tindakan atau kegiatan yang ditawarkan oleh satu pihak ke pihak lain, pada dasarnya bersifat intangible (tidak berwujud fisik) dan tidak mengakibatkan kepemilikan apapun..

Menurut Kotler (2000:488) mengemukakan bahwa terdapat empat karakteristik jasa, antara lain:

1. Intangibility (tidak berwujud)

Jasa tidak berwujud, tidak dapat dilihat, dicicipi, dirasakan, dan 
didengar sebelum membeli.

2. Inseparability(tidak dipisahkan) Jasa tidak dapat dipisahkan dari pembeli jasa itu, baik pembeli jasa itu adalah orang maupun mesin.

3. Variability (keanekaragaman) Jasa sangat beranekarupa karena tergantung siapa yang menyediakannya dan kapan serta dimana disediakan.

4. Perishability (tidak tahan lama) Jasa tidak dapat tahan lama, karenanya tidak dapat disimpan untuk penjualan atau penggunaan dikemudian hari.

\section{B. Perceived Quality (Persepsi Mutu Oleh Pelanggan)}

Kotler (2009:143), mendefinisikan kualitas sebagai keseluruhanciri serta sifat dari suatu produk atau layanan yang berpengaruh padakemampuannya untuk memuaskan kebutuhan yang dinyatakan atauyang tersirat.

Menurut Parasuramanet al., (1998) perceivedquality adalah sesuatu yang mendahului kepuasan pelanggan, kualitasdan ekspetasi mempengaruhi kepuasaan konsumen. Perceived quality merupakan persepsi pelanggan terhadap kualitas atau keunggulan suatu produk atau layanan ditinjau darifungsinya dengan produk-produk lain. Persepsi kualitas merupakanpersepsi dari pelanggan, sehingga persepsi kualitas tidak dapatditemukan secara subjektif. Persepsi pelanggan akan melibatkan apayang penting bagi pelanggan karena setiap pelanggan memilikikepentingan (yang diukur secara relatif) yang berbeda-beda terhadapsuatu produk atau jasa. Maka dapat dikatakan bahwa membahaspersepsi kualitas berarti akan membahas keterlibatan dan kepentingan pelanggan (Simamora, 2004:74).

\section{Perceived Value}

Persepsi adalah proses yang digunakan oleh seorang individu untuk memilih, mengorganisasi dan mengintrepretasi masukan masukan informasi guna menciptakan gambaran dunia yang memiliki arti (Kotler dan Keller, 2007:203). Persepsi tidak hanya dipengaruhi rangsangan fisik tapi juga berhubungan dengan lingkungan sekitar dankeadaan individu yang bersangkutan.

Menurut Kotler (2003:3),Perceived value adalah sekumpulan manfaat yang diharapkan akan diperoleh pelanggan dari produk, nilai pelayanan, nilai karyawan dannilai citra. Nilai produk misalnya kenikmatan menu yang ditawarkan.Nilai pelayanan misalnya ketepatan dalam melayani,keramahannya. Nilai karyawan misalnya pengalamannya, caraberpakaian, cara bicara, sedangkan nilai citra sama dengan image. diharapkan pelanggan untuk dikeluarkan dalam mengevaluasi, mendapatkan menggunakan dan menyingkirkan suatu penawaran pasar, termasuk biaya moneter, waktu, energi dan psikologis (Kotler danKeller, 2009:136).

\section{Loyalitas Konsumen}

1. Pengertian Loyalitas Konsumen Menurut Tjiptono (2016:110), "loyalitas konsumen adalahkomitmen pelanggan terhadap suatu merek, toko atau pemasok berdasarkansifat yang sangat positif dalam pembelian jangka panjang". Dari pengertianini dapat diartikan bahwa kesetiaan terhahadap merek diperoleh karenaadanya kombinasi dari kepuasan dan keluhan.Sedangkan kepuasanpelanggan tersebut hadir dari seberapa besar kinerja perusahaan untukmenimbulkan kepuasan tersebut dengan meminimalkan keluhan sehinggadiperoleh pembelian jangka panjang yang dilakukan oleh konsumen.

\section{Jenis-jenis Loyalitas Konsumen}

Menurut Richard F.Gerson (2004:22) terdapat empat jenis loyalitas yang muncul bila keterikatan rendah dan tinggi diklasifikasi-silang dengan pola pembelian ulang, yang rendah dan tinggi.Adapun jenis-jenis loyalitas konsumen yaitu :

a) Tanpa Loyalitas 
b) Loyalitas yang lemah (Inertia Loyality)

c) Loyalitas Tersembunyi (Laten Loyality)

d) Loyalitas Premium (Premium Loyalty)

3. Indikator Loyalitas Konsumen

Menurut Simamora

(2004:103) loyalitas konsumen merupakan komitmenseorang konsumen terhadap suatu pasar berdasarkan sikap positif dantercermin dalam pembelian ulang secara konsisten. Indikator dari loyalitaskonsumen tersebut adalah:

1) Trust merupakan tanggapan kepercayaan konsumen terhadap pasar.

2) Emotion commitment merupakan komitmen psikologi konsumenterhadap pasar

3) Switching cost merupakan tanggapan konsumen tentang beban yangditerima ketika terjadi perubahan

4) Word of mouth merupakan perilaku publisitas yang dilakukan konsumenterhadap pasar.

5) Cooperation merupakan perilaku konsumen yang menunjukan sikapyang bekerja sama dengan pasar.

\section{E. Pelayanan}

a. Pengertian Pelayanan

$$
\text { Menurut Fandy Tjiptono }
$$

(2016:152), “ pelayanan (service) setiap kegiatan atau manfaat yang dapat diberikan suatu pihak kepada pihak lainnya yang pada dasarnya tidak berwujud dan tidak pula berakibat pemilikan sesuatu dan produksinya dapat atau tidak dapat dikaitkan sengan suatu produk fisik".

Sedangkan Hermin dan Viola (2014:23), "pelayanan adalah daya tarik yang besar bagi para pelanggan sehingga korporat bisnis sering kali menggunakannya sebagai alat untuk menarik minat pelanggan". Menurut Lovelock dalam (Tjiptono 2016:54), "tingkat keunggulan yang diharapkan dan pengendalian atas tingkat keunggulan tersebut untuk memenuhi harapanpelanggan".

b. Faktor - faktor Kualitas Pelayanan

Faktor - faktor yang perlu diperhatikan dalam meningkatkan kualitas pelayanan Wolkins dalam (Tjiptono, 2016:63) adalah :

1) Mengidentifikasi determinan utama kualitas pelayanan

2) Mengelola harapan pelanggan

3) Mengelola bukti

4) Mengembangkan budaya kualitas

c. Dimensi-dimensi Pelayanan

Dimensi kualitas jasa layanan serqual merupakan dimensi kualitas jasa dimana setiap jasa yang ditawarkan memiliki beberapa aspek yang dapat dipergunakan untuk mengetahui tingkat kualitasnya. Menurut Zeithaml, Parasuraman, dan Berry (Fandy Tjiptono,2005:53) telah mengidentifikasi lima dimensi pelayanan berkualitas, yaitu :

1. Bukti langsung (tangibles)

2. Kehandalan (Reliabilty)

3. Daya tanggap (responsiveness).

4. Jaminan (Assurance).

d. Indikator Pelayanan

\subsection{Penelitian Terdahulu}

Penelitian yang dilakukan oleh Viola dan Hermin (2014) yang menelitimengenai Pengaruh Perceived Quality, Perceived Sacrifice, Perceived Value dan Price fairness Terhadap Customer Satisfaction di Taman Sari Rasa Waterpark di Cilacap. Variabel bebas berupa perceivedquality, perceived value dan perceived sacrifice. Variabel terikatberupa customer satisfaction.Hasil penelitian: Perceived value ( $\left.\mathrm{X}_{1}\right)$ merupakan variabel paling dominan terhadap customer satisfaction (Y); Perceived quality $\left(\mathrm{X}_{2}\right)$ berpengaruh positif dan signifikan terhadap customer satisfaction $(\mathrm{Y})$ : Perceived sacrifice $\left(\mathrm{X}_{3}\right)$ 
berpengaruh negatif dan signifikan terhadap customer satisfaction (Y); Pricefairness $\left(\mathrm{X}_{4}\right)$ berpengaruh positif dan signifikan terhadap customersatis faction (Y).

\subsection{Kerangka Fikir}

\section{Gambar 1}

Kerangka Fikir

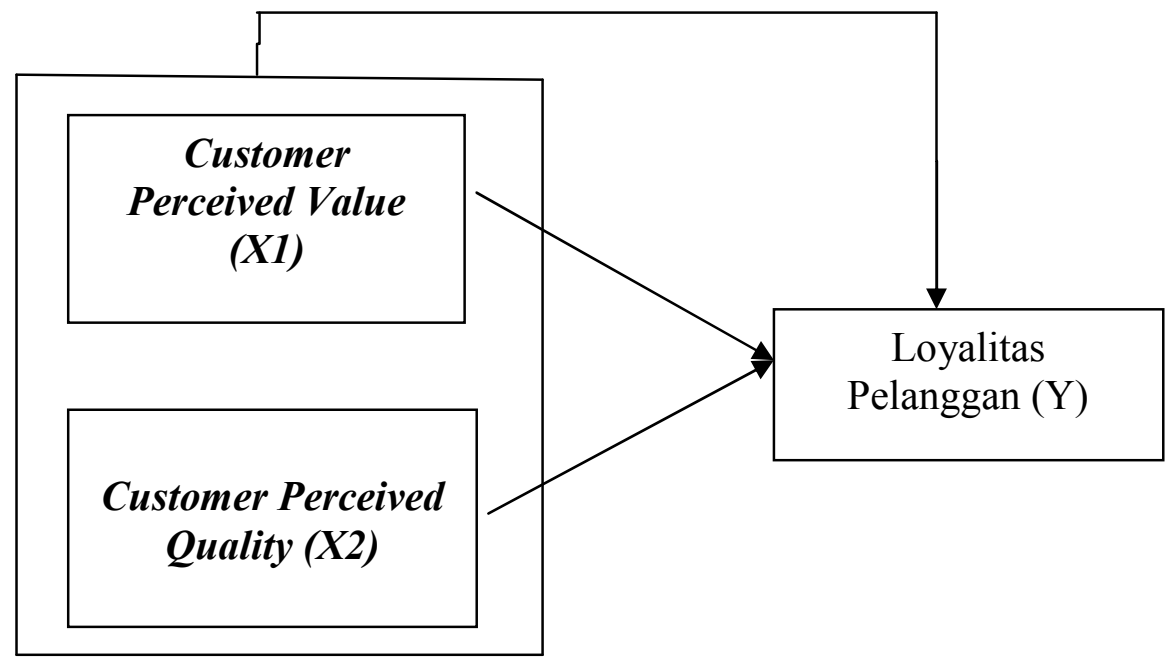

\subsection{Hipotesis}

2.4.1. Terdapat pengaruh secara simultan antara Customer Perceived Value (Persepsi Nilai oleh Pelanggan) dan Customer Perceived Quality (Persepsi Mutu Oleh Pelanggan) terhadap Customer Loyalty (Loyalitas Pelanggan) pada CV. Qyta Dental Persada Laboratory Palembang.

2.4.2. Terdapat pengaruh yang dominan antara Customer Perceived Value (Persepsi Nilai oleh Pelanggan) dan Customer Perceived Quality (Persepsi Mutu Oleh Pelanggan) terhadap Customer Loyalty (Loyalitas Pelanggan) pada CV.Qyta Dental Persada Laboratory Palembang.

\section{METODOLOGI PENELITIAN}

\subsection{Objek Penelitian}

Tempat penelitian dilakukan di kotaPalembang yaitu padaCV.Qyta Dental Persada Laboratory yang berlokasi di JalanCendrawasih 4 Blok.I No.20 Perumahan OPI Jakabaring Palembang Sumatera Selatan.

\subsection{Ruang Lingkup Penelitian}

Dikarenakan adanya beberapa keterbatasan peneliti maka penelitian ini hanya membahas mengenai pengaruh antara Customer Perceived Value (Persepsi Nilai oleh Pelanggan) dan Customer Perceived Quality (Persepsi Mutu Oleh Pelanggan) terhadap Customer Loyalty (Loyalitas Pelanggan) padaCV.Qyta Dental Persada Laboratory Palembang.

\subsection{Desain Penelitian}

Rancangan penelitian menunjukkan kegiatan yang dilakukan oleh peneliti mulai dari perumusan hipotesis sampai 
pada analisisdata. Penelitian ini merupakan desain penelitian Survey. Menurut Hartono (2013:140), desain survey merupakan metode pengumpulan data primer dengan memberikan pertanyaanpertanyaan kepada responden individu. Unit analisis dalam penelitian ini adalah konsumen yang pernah datang dan menggunakan jasa CV.Qyta Dental Persada Laboratory Palembang.

\subsection{Jenis dan Sumber Data}

\subsubsection{Jenis Data}

Dalampenelitian kali ini penulis menggunakan 2 (dua) jenis data yaitu (Sugiono, 2007 : 129).:

a. Data Primer

Data primer adalah data yang langsung dan segera dapat diperoleh dari sumbernya,diamati,dandicatatpertama kalinya.Dalampenelitianini data primer yang digunakan bersumber dari responden yang merupakan konsumen CV.Qyta Dental Persada Laboratory Palembang.

b. Data Sekunder

Data sekunder adalah sumber data yang tidak langsung memberikan data kepada pengumpul data Data sekunder ini merupakan data yang sifatnya mendukung keperluan data primer seperti buku-buku, literatur dan bacaan yang berkaitan dengan permasalahan yang diteliti.

\subsubsection{Sumber Data}

Adapun sumber data yang penulis peroleh dalam melaksanakan penelitian ini adalah berasal dari (Sugiono, 2007 : 132) :

a. Library Research (Studi Kepustakaan)

Penulis mempelajari literatur yang erat hubungannya dengan permasalahan yang dibahas.Penelitian ini menggunakan literatur (kepustakaan), baik berupa buku, catatan, maupun laporan hasil penelitian dari peneliti terdahulu. b. Field Reseach ( Studi Lapangan )

Penulis melakukan penelitian dengan terjun langsung kelapangan untuk memperoleh data-data yang dibutuhkan dalam penyusunan skripsi ini, dalam penelitian lapangan ini, penulis melakukan pengumpulan data dengan cara wawancara dan kuesioner.

\subsection{Populasi dan Sampel}

\subsubsection{Populasi}

Menurut Kuncoro (2013:118), populasi adalah kelompok elemen yanglengkap yang biasanya berupa orang, objek, transaksi atau kejadiandimana kita tertarik untuk mempelajarinya atau menjadi objekpenelitian.Pada penelitian ini yang menjadi populasi adalah seluruh konsumenyangpernah mengunjungi CV.Qyta Dental Persada Laboratory Palembang.

\subsubsection{Sampel}

Sampel adalah suatu himpunan bagian (subset) dari unitpopulasi (Kuncoro, 2013:118).Pengambilan sampel dalam penelitian ini adalah dengan tekniknon probability samplingyaitu menggunakan teknik purposivesampling. Menurut Kuncoro (2103:138), nonprobability samplingadalah teknik pengambilan sampel yang dipilh secara abriter olehpeneliti, dengan kata lain probabilitas masing-masing anggotapopulasi tidak diketahui, sedangkan teknik purposive sampling adalahteknik penentuan sampel dengan pertimbangan tertentu.

Adapun sampel dalam penelitian ini adalah konsumen yang pernah mengunjungi CV.Qyta Dental Persada Laboratory Palembang yang tercatat dalam 1 tahun terakhir dengan jumlah kunjungan lebih dari $2 \mathrm{x}$ kunjungan, adapun sampel yang digunakan adalah sejumlah 50 orang yang secara random ditemui oleh penulis pada saat penelitian berlangsung 


\subsection{Definisi Operasional Variabel}

Tabel 1

Definisi Operasional Variabel

\begin{tabular}{|c|c|c|c|}
\hline Variabel & $\begin{array}{c}\text { Definisi } \\
\text { Operasional } \\
\text { Variabel }\end{array}$ & Indikator & Parameter \\
\hline $\begin{array}{l}\text { Perceived } \\
\text { Value (X1) }\end{array}$ & $\begin{array}{l}\text { Sekumpulan } \\
\text { manfaat yang } \\
\text { diharapkan } \\
\text { akan } \\
\text { diperoleh } \\
\text { pelanggan dari } \\
\text { produk, nilai } \\
\text { pelayanan, nilai } \\
\text { karyawan dan } \\
\text { nilai citra. Nilai } \\
\text { produk } \\
\text { misalnya } \\
\text { kenikmatan } \\
\text { menu yang } \\
\text { ditawarkan }\end{array}$ & $\begin{array}{l}\text { a. Emotional value } \\
\text { b. Social value } \\
\text { c. Quality value } \\
\text { d. Price value }\end{array}$ & 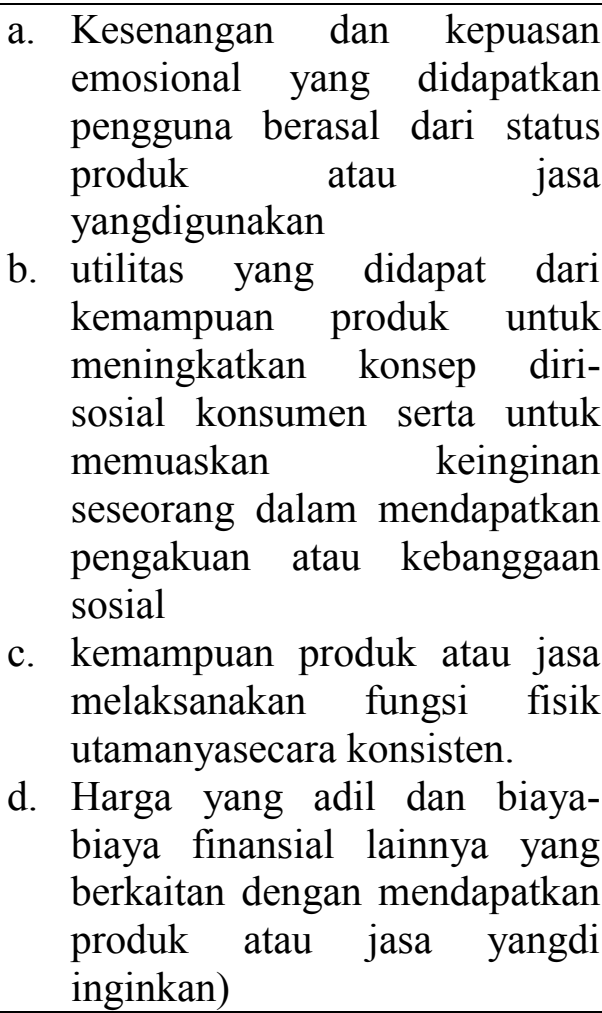 \\
\hline $\begin{array}{l}\text { Perceived } \\
\text { Quality(X2) }\end{array}$ & $\begin{array}{l}\text { Proses } \\
\text { pelanggan } \\
\text { terhadap } \\
\text { keseluruhan } \\
\text { kualitas atau } \\
\text { keunggulan } \\
\text { suatu produk } \\
\text { atau jasa } \\
\text { layanan apa } \\
\text { berkaitan } \\
\text { dengan } \\
\text { yang } \\
\text { diharapkan oleh } \\
\text { pelanggan }\end{array}$ & $\begin{array}{l}\text { a.Performance } \\
\text { b. Service ability } \\
\text { c. Durability } \\
\text { d. Reliability } \\
\text { e. Feature } \\
\text { f.Conformance } \\
\quad \text { with } \\
\quad \text { specifications, } \\
\text { g. Fit and finish }\end{array}$ & $\begin{array}{l}\text { a. karakteristik operasi suatu } \\
\text { produk kemampuan } \\
\text { b.mencerminkan memberikan } \\
\text { perusahaan sehubungan dengan } \\
\text { pelayanan se } \\
\text { produk tersebut. } \\
\text { b. mencerminkan umur ekonomis } \\
\text { suatu produk. } \\
\text { c. konsisten kinerja suatu produk } \\
\text { dari pembelian satuke pembelian } \\
\text { lainnya } \\
\text { d. tambahan untuk menjadi } \\
\text { pembeda yang penting untuk dua } \\
\text { perusahaan yang tampak sama. } \\
\text { e. Pandangan mengenai kualitas } \\
\text { proses manufaktur yang sesuai } \\
\text { dengan spesifikasi yang telah } \\
\text { ditentukan dan diuji. }\end{array}$ \\
\hline
\end{tabular}




\begin{tabular}{|c|c|c|c|}
\hline $\begin{array}{c}\text { Loyalitas } \\
\text { Pelanggan } \\
\text { (Y) }\end{array}$ & $\begin{array}{l}\text { Komitmen } \\
\text { mendalam } \\
\text { untuk membeli } \\
\text { suatu produk } \\
\text { atau jasa secara } \\
\text { konsisten di } \\
\text { masa yang akan } \\
\text { datang, }\end{array}$ & $\begin{array}{l}\text { 1. Pembelian } \\
\text { ulang (Repeat } \\
\text { purchase) } \\
\text { 2. Pembelian } \\
\text { terhadap lini } \\
\text { produk } \\
\text { (Purchases } \\
\text { across product } \\
\text { \& services } \\
\text { lines) } \\
\text { 3. Referensi } \\
\text { (Reference } \\
\text { others) } \\
\text { 4. Tidak mudah } \\
\text { terpengaruh. }\end{array}$ & $\begin{array}{l}\text { 1. Konsumen tertarik untuk } \\
\text { melakukan pembelian ulang } \\
\text { 2. Konsumen dapat membeli lini } \\
\text { produk lain } \\
\text { 3. Memberikan referensi kepada } \\
\text { oang lain } \\
\text { 4. Tidak mudah terpengaruh } \\
\text { terhadap perusahaan lain } \\
\text { sebelum melakukan percobaan } \\
\text { pembelian }\end{array}$ \\
\hline
\end{tabular}

\subsection{TEKNIK ANALISIS}

\subsubsection{Pengujian Instrumen Penelitian}

\section{A. Uji validitas}

Menurut Ghozali (2013:52), uji validitas digunakan untuk mengukur sah atau valid tidaknya suatu kuesioner. Suatu kuesioner dikatakan valid jika pernyataan pada kuesioner mampu mengungkapkan suatu yang akan diukur oleh kuesioner tersebut.. Penyataan dikatakan valid ketika nilai signifikasi konstruk menunjukkan hasil yang signifikan $(p$-value $<0,05)$ dan lebih dari 0,3 .

\section{B. Uji reliabilitas}

Suatukuesioner dikatakan reliabel atau handal, jika jawaban seseorang terhadap pernyataan adalah konsisten atau stabil dari waktu kewaktu (Ghozali, 2013:47). Pengukuran instrumen dalam penelitianini menggunakan uji statistik Cronbach's Alpha, suatu konstrukatau variabel dikatakan reliabel jika memberikan nilai Cronbach's Alpha 0,70 (Nunnaly dalam Ghozali, 2013:48).

\subsubsection{Analisis Data}

Persamaan analisis regresi berganda yang digunakan adalah sebagai berikut:

$$
\begin{aligned}
& \mathrm{Y}=\mathrm{a}+\mathrm{b}_{1} \mathrm{X}_{1}+\mathrm{b}_{2} \mathrm{X}_{2}+\mathrm{e} \\
& \text { Dimana: } \\
& \mathrm{Y}=\text { Customer Loyalty } \\
& \mathrm{X}_{1}=\text { Perceived Value }
\end{aligned}
$$

$$
\begin{aligned}
& \mathrm{X}_{2}=\text { Perceived Quality } \\
& \mathrm{a}=\text { Konstanta } \\
& \mathrm{b}_{1}=\text { Koefisien regresi perceived } \\
& \text { value } \\
& \mathrm{b}_{2}=\text { Koefisien regresi perceived } \\
& \text { quality } \\
& \mathrm{e}=\text { Error }
\end{aligned}
$$

\section{HASIL PENELITIAN DAN}

\section{PEMBAHASAN}

\subsection{Karakteristik Responden}

\begin{tabular}{|c|c|c|}
\hline \multicolumn{3}{|c|}{ Usia } \\
\hline Usia & $\begin{array}{c}\text { Jumlah } \\
\text { Responden }\end{array}$ & $\%$ \\
\hline 19-25 tahun & 4 & $8 \%$ \\
\hline 26-30 tahun & 10 & $20 \%$ \\
\hline 31-35 tahun & 15 & $30 \%$ \\
\hline$>36$ tahun & 21 & $42 \%$ \\
\hline Total & 50 & $100 \%$ \\
\hline
\end{tabular}

Terdapat karakteristik responden yang dimasukkan dalam penelitian, yaitu berdasarkan usia, tingkat pendidikan, masa kerja, dan jenis kelamin.

\section{a. Usia}

Pada tabel berikut ini menunjukkan pengelompokkan responden berdasarkan jenis kelamin :

\section{Tabel 2}

Karakteristik Responden berdasarkan

Dari tabel di atas yang berdasarkan usia, responden yang yang berumur lebih dari 36 tahun merupakan yang paling 
banyak, yaitu 21 orang atau $42 \%$ dan yang paling sedikit berumur 19-25 yaitu 4 orang atau hanya $8 \%$.

\section{b. Jenis Kelamin}

Pada tabel berikut ini menunjukkan pengelompokan responden berdasarkan pada jenis kelamin :

Tabel 3

Karakteristik Responden berdasarkan Jenis Kelamin

\begin{tabular}{|c|c|c|}
\hline $\begin{array}{c}\text { Jenis } \\
\text { Kelamin }\end{array}$ & $\begin{array}{c}\text { Jumlah } \\
\text { Responden }\end{array}$ & $\%$ \\
\hline Laki-laki & 37 & $74 \%$ \\
\hline Perempuan & 13 & $26 \%$ \\
\hline Total & 50 & $100 \%$ \\
\hline
\end{tabular}

Dari data di atas dapat di ketahui yaitu responden laki-laki merupakan responden terbanyak yaitu 37 orang atau $74 \%$ dan 13 orang atau $26 \%$ berjenis kelamin perempuan.

\section{c. Tingkat Pendidikan}

Pada tabel berikut ini menunjukkan pengelompokan responden berdasarkan pada tingkat pendidikan :

Tabel 4

Karakteristik Responden berdasarkan Tingkat Pendidikan

\begin{tabular}{|c|c|c|}
\hline $\begin{array}{c}\text { Tingkat } \\
\text { Pendidikan }\end{array}$ & $\begin{array}{c}\text { Jumlah } \\
\text { Responden }\end{array}$ & $\%$ \\
\hline SLTA & 18 & $36 \%$ \\
\hline D3 & 13 & $26 \%$ \\
\hline $\mathrm{S} 1$ & 19 & $38 \%$ \\
\hline Total & 50 & $100 \%$ \\
\hline
\end{tabular}

Dari tabel di atas dapat kita ketahui bahwa berdasarkan tingkat pendidikan S1 merupakan reponden paling banyak yaitu 19 orang atau $38 \%$, sedangkan yang paling rendah adalah pada tingkat pendidikan D3yaitu sebanyak 13 orang atau $26 \%$.

\subsection{Pengujian Instrumen Penelitian (Validitas dan Reliabilitas)}

\section{Tabel 5}

\section{Uji Validitasdan Uji Reliabilitas}

\begin{tabular}{|c|c|l|l|l|}
\hline $\begin{array}{c}\text { Items } \\
\text { (Variabel) }\end{array}$ & $\begin{array}{c}\text { Total Pearson } \\
\text { Correlation }\end{array}$ & Validitas & $\begin{array}{c}\text { Alpha } \\
\text { Cronbach }\end{array}$ & Reliabilitas \\
\hline X1 & 0,512 & & & \\
X1.1 & 0,611 & & & \\
X1.2 & 0,731 & Valid & 0,775 & Reliabel \\
X1.3 & 0,691 & & & \\
X1.4 & 0,554 & & & \\
X1.5 & 0,665 & & & \\
X1.6 & 0,709 & & & \\
X1.7 & 0,651 & & & \\
X1.8 & & & \\
\hline X2 & 0,654 & & \\
X2.1 & 0,709 & & & \\
X2.2 & 0,623 & & & \\
X2.3 & 0,554 & & & \\
X2.4 & 0,680 & & \\
X2.5 & 0,771 & & \\
X2.6 & 0,704 & & \\
X2.7 & & & \\
\hline
\end{tabular}




\begin{tabular}{|c|c|c|c|c|}
\hline Y & & & & \\
Y.1 & 0,632 & & & \\
Y.2 & 0,766 & Valid & 0,785 & Reliabel \\
Y.3 & 0,709 & & & \\
Y.4 & 0,661 & & & \\
\hline
\end{tabular}

\subsection{Analisis Regresi Linier Berganda}

Tabel 6

Analisis Regresi Linier Berganda Coefficients $^{\mathrm{a}}$

\begin{tabular}{|c|c|c|c|c|c|c|}
\hline & \multicolumn{2}{|c|}{ Unstandardized Coefficients } & \multirow{2}{*}{$\begin{array}{c}\text { Standardized } \\
\text { Coefficients } \\
\text { Beta }\end{array}$} & \multirow[t]{2}{*}{$\mathrm{t}$} & \multirow[t]{2}{*}{ Sig. } \\
\hline \multicolumn{2}{|c|}{ Model } & B & Std. Error & & & \\
\hline & (Constant) & 2.093 & .802 & & 2.610 & .012 \\
\hline 1 & $\begin{array}{l}\text { CPV (X1) } \\
\text { CPQ (X2) }\end{array}$ & $\begin{array}{c}.321 \\
.563\end{array}$ & $\begin{array}{l}.136 \\
.133\end{array}$ & $\begin{array}{l}.333 \\
.609\end{array}$ & $\begin{array}{l}2.364 \\
4.231\end{array}$ & $\begin{array}{l}.022 \\
.000\end{array}$ \\
\hline
\end{tabular}

a. Dependent Variable: CL (Y)

Adapun persamaan regresi linier berganda adalah sebagai berikut :

$$
\begin{aligned}
& Y=a+b 1 X 1+b 2 X 2 \\
& Y=2,093+0,321 X 1+0,563 X 2
\end{aligned}
$$

Dimana:

$\mathrm{X} 1=$ Variabel Independent (Customer Perceived Value)

X2=Variabel Independent (Customer Perceived Quality)

$\mathrm{Y}=$ Variabel dependen (Customer loyality)

$\mathrm{a}=$ Konstanta

$\mathrm{b}=$ Koefisien garis regresi

Adapun maksud dari persamaan linier berganda tersebut adalah sebagai berikut :

1. Koefisien regresi (b) X1 sebesar 0,321 memberikan arti bahwa Customer Perceived Value berpengaruh positif terhadap Customer Loyality terhadap CV.Qyta Dental Persada Laboratory Palembang (Y). Hal ini menunjukkan bahwa dengan penambahan 1 satuan Customer Perceived Value, maka akan terjadi peningkataan loyalitas konsumen sebesar 0,321 dan begitu pun sebaliknya.

2. Koefisien regresi (b) X2 sebesar 0,563 memberikan arti bahwa Customer Perceived Quality berpengaruh positif terhadap Customer Loyality terhadap CV.Qyta Dental Persada Laboratory Palembang (Y). Hal ini menunjukkan bahwa dengan penambahan 1 satuan Customer Perceived Quality, maka akan terjadi peningkataan loyalitas konsumen sebesar 0,563 dan begitu pun sebaliknya.

3. Konstanta didapat angka sebesar 2,093, dimana hal ini berarti apabila Customer Perceived Value dan Customer Perceived Quality sama dengan nol maka nilai dari Loyalitas Konsumen adalah sebesar 2,093. 


\subsection{Koofesien Determinasi}

\section{Tabel 7}

\section{Koofisien Determinasi}

\begin{tabular}{|c|c|c|c|c|}
\hline \multicolumn{5}{|c|}{ Model Summary $^{b}$} \\
\hline Model & $\mathrm{R}$ & R Square & $\begin{array}{l}\text { Adjusted R } \\
\text { Square }\end{array}$ & $\begin{array}{l}\text { Std. Error of } \\
\text { the Estimate }\end{array}$ \\
\hline 1 &, $582^{a}$ & ,338 & ,295 & 2,1911 \\
\hline
\end{tabular}

Dari hasil pengolahan data komputerisasi dengan menggunakan program SPSS 19 maka diperoleh koofisien determinasi $\left(\mathrm{R}^{2}\right)$ sebesar 0,338 . Hal ini menunjukkan bahwa sebesar 33,8\% Loyalitas Pelanggan dapat dijelaskan oleh variabel Customer Perceived Valuedan variabel Customer Perceived Qualitysedangkan sisanya 66,2\% dijelaskan oleh faktor-faktor lain yang tidak termasuk dalam penelitian ini.

\subsection{Uji t (Parsial)}

Tabel 8

Uji t (Parsial)

Coefficients $^{a}$

\begin{tabular}{|c|c|c|c|c|c|c|}
\hline \multicolumn{2}{|c|}{ Model } & \multicolumn{2}{|c|}{ Unstandardized Coefficients } & \multirow{2}{*}{$\begin{array}{c}\text { Standardized } \\
\text { Coefficients } \\
\text { Beta }\end{array}$} & \multirow[t]{2}{*}{$\mathrm{t}$} & \multirow[t]{2}{*}{ Sig. } \\
\hline & & $B$ & Std. Error & & & \\
\hline & (Constant) & 2.093 & .802 & & 2.610 & .012 \\
\hline 1 & $\begin{array}{l}\text { CPV (X1) } \\
\text { CPQ (X2) }\end{array}$ & $\begin{array}{c}.321 \\
.563\end{array}$ & $\begin{array}{l}.136 \\
.133\end{array}$ & $\begin{array}{l}.333 \\
.609\end{array}$ & $\begin{array}{l}2.364 \\
4.231\end{array}$ & $\begin{array}{l}.022 \\
.000\end{array}$ \\
\hline
\end{tabular}

a. Dependent Variable: CL (Y)

Selanjutnya dari tabel tersebut dapat dijelaskan sebagai berikut:

\section{Variabel Customer Perceived Value \\ Hasil pengujian diperoleh nilai $\mathrm{t}$} untuk variabel Customer Perceived Value menunjukkan nilai $\mathrm{t}=2,364$ dengan nilai signifikansi sebesar $0,022<0,05$. Dengan nilai signifikansi dibawah 0,05 tersebut menunjukkan bahwa Customer Perceived Value memiliki pengaruh yang signifikan terhadap Loyalitas Pelanggan. Hal ini berartiHipotesis1diterima.Arah diterima. Arah koefisien regresi positif berarti bahwa Customer Perceived Value memiliki pengaruh positif yang signifikan terhadap Loyalitas Pelanggan. Semakin besar Customer Perceived Value yang diberikan perusahaan akan semakin tinggi pula loyalitas pelanggan, sebaliknya semakin rendah Customer Perceived Value yang diberikan perusahaan semakin rendah pula loyalitas pelanggan.

\section{Variabel Customer Perceived Quality}

Hasil pengujian diperoleh nilai $\mathrm{t}$ untuk variabel Customer Perceived Quality menunjukkan nilai $\mathrm{t}=4,231$ dengan nilai signifikansi sebesar $0,000<0,05$. Dengan nilai signifikansi dibawah 0,05 tersebut menunjukkan bahwa Customer Perceived Quality memiliki pengaruh yang signifikan terhadap Loyalitas Pelanggan. Hal ini berarti Hipotesis 1 diterima. Arah diterima. Arah koefisienregresi positif berarti bahwa Customer Perceived Quality memiliki pengaruh positif yang signifikan terhadap 
Loyalitas Pelanggan. Semakin besarvariabel Customer Perceived Quality yang diberikan perusahaanakan semakin tinggi pula loyalitas pelanggan, sebaliknya semakin rendah Customer Perceived Quality yang diberikan perusahaan semakin rendah pula loyalitas pelanggan.

\subsection{Ujif (Pengujian hipotesis secara simultan)}

Hasil perhitungan regresi secara simultan (bersama-sama) dapat dilihat padaTabelberikut

Tabel9

Tabel Uji f (Simultan)

\begin{tabular}{|c|c|c|c|c|c|c|}
\hline & \multicolumn{6}{|c|}{ ANOVA $^{\mathbf{b}}$} \\
\hline \multicolumn{2}{|c|}{ Model } & $\begin{array}{l}\text { Sumof } \\
\text { Squares }\end{array}$ & df & MeanSquare & $\mathrm{F}$ & Sig. \\
\hline 1 & Regression & 1.685 & 2 & .562 & 7.838 & $.000^{\circ}$ \\
\hline & \multirow{2}{*}{ Residual } & 3.295 & 47 & .072 & & \\
\hline & & 4.980 & 49 & & & \\
\hline
\end{tabular}

a. Predictors: (Constant), CPV (X1), CPQ (X2)

b. Dependent Variable: $\mathrm{CL}(\mathrm{Y})$

Pengujian pengaruh variabel bebas secara bersama-sama terhadap variabel terikatnya dilakukan dengan menggunakan uji F. Hasil perhitungan statistik menunjukkan nilai $\mathrm{F}$ hitung $=7,838$ dengan signifikansi sebesar 0,000 $<0,05$. Dengan nilai signifikansi dibawah 0,05 menunjukkan bahwa secara bersama-sama Customer Perceived Value dan Customer Perceived Quality mempunyai pengaruh yang positif dan signifikan terhadap Loyalitas Pelanggan CV.Qyta Dental Persada Laboratory Palembang.

\subsection{Pembahasan}

Berdasarkan hasil analisis, Customer Perceived Value dan Customer Perceived Quality mempunyai pengaruh terhadap Loyalitas Pelanggan CV.Qyta Dental Persada Laboratory Palembang baik secara parsial maupun secara simultan. Uji hipotesis Customer Perceived Value secara simultan ditunjukkan dengan nilai $\mathrm{p}$ $(\mathrm{sig})=0,022<0,05$ kemudian Uji hipotesis Customer Perceived Quality secara simultan ditunjukkan dengan nilai $\mathrm{p}(\mathrm{sig})=$
$0,000<0,05$. Dengan demikian terbukti bahwa variabel Customer Perceived Value dan Customer Perceived Quality mempunyai pengaruh terhadap Loyalitas Pelanggan.

Banyak hal yang dapat dilakukan oleh CV.Qyta Dental Persada Laboratory Palembang dalam hal meningkatkan Nilai dan Kualitas produk mereka. Pihak perusahaan pun harus memiliku pembeda / keunggulan dengan perusahaan sejenis lainnya agar konsumen memiliki alasan mengapa mereka harus memilih CV.Qyta Dental Persada Laboratory Palembang dibandingkan dengan perusahaan lain. Hal ini penting untuk dipedomani agar tercipta loyalitas pelanggan.Usaha yang dilakukan CV.Qyta Dental Persada Laboratory Palembanguntuk menciptakan kepuasan konsumen lebih cenderung mempengaruhi sikap konsumen.Sedangkan konsep loyalitas konsumen lebih menerangkan kepada perilaku pembelinya. 
V. KESIMPULAN DAN SARAN

A. Kesimpulan

1. Berdasarkan hasil yang diperoleh, variabel Customer Perceived Value dan Customer Perceived Quality mempunyai pengaruh terhadap Loyalitas Pelanggan CV.Qyta Dental Persada Laboratory Palembang, maka sebaiknya dalam setiap pengambilan kebijakan strategis oleh perusahaan maka perlu memperhatikan unsur unsur nilai dan kualitas dari persepsi pelanggan.

2. Berdasarkan hasil analisis regresi linier berganda, dengan nilai Konstanta didapat angka sebesar 2,093, dimana hal ini berarti apabila Customer Perceived Value dan Customer Perceived Quality sama dengan nol maka nilai dari Loyalitas Pelanggan adalah sebesar 2,093

3. Adapun koefisien arah Customer Perceived Value (X1) yang mempengaruhi Loyalitas Pelanggan CV.Qyta Dental Persada Laboratory Palembang (Y) diperoleh koefisien regresi (b) sebesar 0,321 dengan tanda positif. Berdasarkan hasil tersebut maka dapat disimpulkan bahwa apabila Customer Perceived Value meningkat atau naik $1 \%$ maka Loyalitas Pelanggan CV.Qyta Dental Persada Laboratory Palembang akan meningkat sebesar 32,1\%.

4. Adapun koefisien arah Customer Perceived Quality (X2) yang mempengaruhi Loyalitas Pelanggan CV.Qyta Dental Persada Laboratory Palembang (Y) diperoleh koefisien regresi (b)sebesar 0,563 dengan tanda positif. Berdasarkan hasil tersebut maka dapat disimpulkan bahwa apabila Customer Perceived Quality meningkat atau naik $1 \%$ maka Loyalitas Pelanggan CV.Qyta Dental Persada Laboratory Palembang akan meningkat sebesar $56,3 \%$.

\subsection{Saran}

1. Pihak CV.Qyta Dental Persada Laboratory Palembang harus tetap memperhatikan, dan mempertahankan faktor faktor yang dapat mempengaruhi loyalitas pelanggan, yaitu dengan memperhatikan Nilai dari sisi pelanggan. Hal-hal tersebut mencakup manfaat / benefit yang dirasakan oleh pelanggan setelah menggunakan jasa dan membeli produk produk dari CV.Qyta Dental Persada Laboratory Palembang. Manfaat yang pelanggan peroleh haruslah sesuai dengan biaya yang mereka keluarkan dalam memperoleh jasa yang mereka inginkan

2. Selain daripada itu, pihak pengelola pun tidak hanya mengutamakan Nilai Jasa namun harus memperhatikan Kualitas dari jasa tersebut. Persepsi pelanggan terhadapkualitas atau keunggulan suatu produk atau layanan ditinjau dari fungsinya dengan produkproduk lain. Jadi penting bagi CV.Qyta Dental Persada Laboratory Palembang untuk memperhatikan Persepsi kualitas berdasarkan persepsi dari pelanggan, sehingga persepsi kualitas tidak dapatditemukan secara subjektif.

\section{DAFTAR PUSTAKA}

Gerson, Richard. F. 2004. Mengukur Kepuasan Pelanggan. Jakarta: PPM

Ghozali, Imam. 2013. Aplikasi Analisis Mulitivariate dengan Program IBM SPSS21 Update PLS Regresi. Semarang: Badan Penerbit UniversitasDiponegoro.

Hanirto, Kevin Julian. 2012. Analisis Pengaruh Perceived Benefits danPerceivedSacrifice Terhadap Customer Satisfaction. Skripsi: UniversitasMulitimedia Nusantara.

Hartono, Jogiyanto. 2013. Metode Penelitian Bisnis. Yogyakarta: BPFE. 
Hermin dan Viola. 2014. Pengaruh Perceived Quality, Perceived Sacrifice,Perceived Value dan Price Fairness Terhadap Customer SatisfactionTaman Sari Rasa Waterpark Cilacap. Universitas Muhammadiyah Purwokerto.

Kotler, Philip. 2003. The Art Of Building Customer Value. Jakarta:LPMB

Kotler, Philip dan Keller, Kevin Lane. 2007. Manajemen Pemasaran. Edisi Kedua,Jilid 2. Jakarta: Erlangga

Kotler, Philip dan Keller. 2009. Manajemen Pemasaran. Jilid 1. Jakarta: Erlangga

Kuncoro, Mudrajat. 2013. Metode Riset Untuk Bisnis dan Ekonomi. Jakarta:Erlangga.

Rangkuti, Ferdy. 2008. Teknik Pengelolaan Brand Equity dan StrategiPengembangan Merek. Jakarta: Gramedia Pustaka Utama.

Siamamora, 2004. Panduan Riset Perilaku Konsumen. Jakarta: PT GramediaPustaka Utama.

Sugiyono, 2007. Metodologi Penelitian Bisnis: Pendekatan Kuantitatif, Kualitatifdan R\&D. Bandung: CV Alfabeta.

Tjiptono, Fandy. 2016. Marketing Scales. Yogyakarta: Penerbit ANDI.

Widjaja, Bernard. 2009. Lifesyle Marketing, Paradigma Baru Pemasaran BisnisJasa dan Lifesyle. Jakarta: PT. Gramedia Pustaka Utama.

Zeithaml L., Valerie A., A. Parasuraman., Leonardo L. Berry. (2008). Servqual amultiple-item scale for measuring consumer perception of service quality.

Journal of Retailing. Vol. 64, pp.12-37 